\title{
Prediction of Wave Propagation in Buildings Using Data from a Single Seismometer
}

\author{
by Ming Hei Cheng, Monica D. Kohler, and Thomas H. Heaton
}

\begin{abstract}
Crowd-sourced seismic networks in buildings collect important scientific data, in addition to allowing a diverse audience to visualize the vibrations of buildings. Visualization of a building's deformation requires spatiotemporal interpolation of motions from seismometers that are located wherever the crowd places them. In many cases, a crowd-sourced building network may actually be just a single seismometer. A method to rapidly estimate the total displacement response of a building based on limited observational data, in some cases from only a single seismometer, is presented. In general, the earliest part of the response is simulated by assuming a vertically propagating shear wave. Later motions are simulated using mode shapes derived from a beam model (a shear beam, or more generally a Timoshenko beam), the parameters of which are determined from the ratios of the modal frequencies and the building's exterior dimensions. The method is verified by (1) comparing predicted and actual records from a 54-story building in downtown Los Angeles, California, and (2) comparing finite-element simulations of the 17-story University of California, Los Angeles (UCLA) Factor building. The response of each of these buildings can be simulated with a simple shear beam. The importance of including the traveling wave part of the solution depends on the characteristics of the base ground shaking; the traveling wave becomes more apparent as the excitation becomes more impulsive. The method can be straightforwardly applied to multiple instrumented buildings, resulting in a tool to visualize linear elastic motions of those buildings.
\end{abstract}

\section{Introduction}

Crowd-sourced seismic networks that enable rapid expansion of sensor deployments in multiple buildings are currently under development in the United States, including the Community Seismic Network (Clayton et al., 2011) and the Quake-Catcher Network (Cochran et al., 2009, 2011). These networks can potentially provide many new observations that might not be obtained by traditional networks. Installation and maintenance of stations is largely the responsibility of volunteers; it is important to help them understand the science they are facilitating. In the case of a building seismic array, the data can be used to produce movies of the building's deformation in earthquakes. In a crowd-sourced network, station locations are typically chosen for reasons that are unrelated to the optimal design of a seismic network. In particular, there may be instances in which a single seismometer is the only data source that is available from a building. Furthermore, it may not be practical to construct a detailed finite-element model of the building; even if there were sufficient resources to construct a dynamic model, the structural design of the building may not be available. Transfer functions can be used to relate the input and output of a time-invariant system (e.g., Snieder and Safak, 2006; Kohler et al., 2007). Simulated time series from a computational model or seismic records from both locations are needed to obtain the corresponding transfer function. In this study, we present a new computational tool to estimate and visualize the linear elastic motions of existing buildings that have recorded earthquake shaking, given in some instances only a single seismometer deployed in the building. The method is verified with the observations from dense structural array data and numerical simulations.

Using the time series from a single station in a building, we show how the linear elastic displacement response predicted for all floors based solely on modal decomposition of the first few modes does not adequately capture the initial impulsive response. This can lead to an underestimation of floor displacement, especially if maximum floor response occurs during the coherent, impulsive ground motion before the resonant mode response dominates (Iwan, 1997). To address this issue, we decompose building motion due to earthquake excitation into the broadband traveling wave component and the low-frequency resonant mode component. Computed mode shapes of the building are used to relate the resonant mode response from an observation on one 
floor to calculated predictions for response on the other floors.

The application of fixed-base shear beam mode shapes to tall buildings is often a useful first-order approximation (e.g., Jennings, 2003), particularly if the observed frequency ratios match those of the shear beam (i.e., $f_{1}, 3 f_{1}, 5 f_{1}$, etc., in which $f_{1}$ is the fundamental translational frequency in a particular direction). The building response of the other floors can then be assembled. The method presented here is suitable if building response remains linear elastic.

\section{Building Response during Earthquakes}

Given a particular ground motion, the linear elastic building response due to earthquake excitation can be computed in two complementary bases: the traveling wave representation and the resonant mode representation. As is common in wave problems, the choice of an appropriate coordinate frame can greatly simplify the description of the wave. In particular, the use of a modal coordinate frame is especially helpful in problems that are primarily composed of standing waves; resonance phenomena are typically easier to analyze with a modal coordinate frame. On the other hand, traveling waves are usually easier to represent using characteristic coordinate frames (e.g., Ray theory). This is especially true for waves having an intrinsic velocity that is independent of the frequency (nondispersive). Given no observational limitations, either the modal or the characteristic coordinate frame can be used to describe the entire motion of a building, but it is easiest to simulate the earliest parts of the motion as traveling waves (characteristic coordinates) and the later parts as standing waves (modes). Kanai (1965) suggested that multiple reflections of waves in an elastic layer could be used to study seismic vibration of a structure, as well as to design a seismic resistant structure. Equation (1) shows the wave propagation solution of a continuous fixed-base shear beam model (e.g., Iwan, 1997; Sasani et al., 2006):

$$
\begin{aligned}
u(t, z)= & \sum_{k=0}^{\infty}(-1)^{k} u_{g}\left(t-\frac{2 k H+z}{c}\right) * \xi\left(\frac{2 k H+z}{c}, t\right) \\
& -\sum_{k=1}^{\infty}(-1)^{k} u_{g}\left(t-\frac{2 k H-z}{c}\right) * \xi\left(\frac{2 k H-z}{c}, t\right),
\end{aligned}
$$

in which $u(t, z)$ is the (total) displacement response, $t$ is time, $z$ is height from the ground, $H$ is the total building height, $c$ is the traveling wave velocity, $\xi$ (distance traveled, $t$ ) is the damping function, $*$ is the convolution operator, $u_{g}(t)$ is the horizontal ground motion, and $k$ is the index of summation indicating transit leg. This closed-form solution is true for a shear beam in which the traveling wave velocity is independent of the wavelength, that is, wave velocity $c=(4 H) / T_{1}$. To include wave dispersion, convolution with functions that include the phase information would be necessary, but the solution becomes complicated. Nevertheless, the wave solution for a shear beam is a good approximation for displacement response in buildings when the dispersion effect is small (i.e., when the initial impulse begins its first transit leg up the building). The damping function is typically simulated with a minimum-phase causal filter for which the amplitude spectrum decays exponentially with the product of frequency and travel time. This introduces a frequency-dependent group delay (lower frequencies have larger group delays); that is, damping introduces some degree of dispersion.

Alternatively, displacement response in buildings can be obtained by summing an infinite number of resonant modes, each with a specific phase (e.g., Roberts and Lutes, 2003):

$$
u^{\mathrm{rel}}(t, z)=\sum_{i=1}^{\infty} u_{i}^{\mathrm{rel}}(t, z)=\sum_{i=1}^{\infty} \phi_{i}(z) q_{i}(t)
$$

in which $u^{\text {rel }}(t, z)$ is the (relative) building response of the $i$ th mode, $\phi_{i}(z)$ is the $i$ th mode shape, $q_{i}(t)$ is the damped modal displacement at the $i$ th modal coordinate, and $i$ is the index of summation. Because $u^{\mathrm{rel}}(t, z)$ is displacement in a noninertial frame, the displacement measured by a seismometer is

$$
u(t, z)=u^{\mathrm{rel}}(t, z)+u_{g}(t) .
$$

Dispersion effects are implicitly incorporated into this solution. If viscous damping is proportional to some linear combination of the masses and stiffnesses (Rayleigh damping), then the mode shapes are simple functions of $z$, and the time histories solve linearly damped single-degree-of-freedom linear oscillator problems. Using a single record to determine the appropriate transient response of each mode is problematic, especially during the initial upward traveling impulse. To determine the motion in the modal coordinate frame, we would need to sum the records from each floor weighted by the mode shape function. To get around this limitation, we present a fast and robust method that captures the initial broadband impulse traveling along the building height by the wave solution (equation 1) for the early parts of the motion and transitions to subsequent low-frequency building displacement response using the resonant mode solution (equation 3). If the duration of the ground motion is short compared with the travel time up the building, then the waveform of the upward traveling wave can be identified because it is separated in time from later reflected phases.

To transition from traveling wave solution to resonant mode solution, we use a linear transition function that begins at the time when the initial impulse first reaches the roof of the building (i.e., $t=T_{1} / 4$ from the start of base excitation) and ends at the time when the initial impulse finishes its first reflection back to the building's base (i.e., $t=T_{1} / 2$ from the start of base excitation), in which $T_{1}$ is the fundamental period of the building. The total estimated displacement response $\hat{u}(t, z)$ is defined as a function of weighted traveling wave and weighted modal solution: 

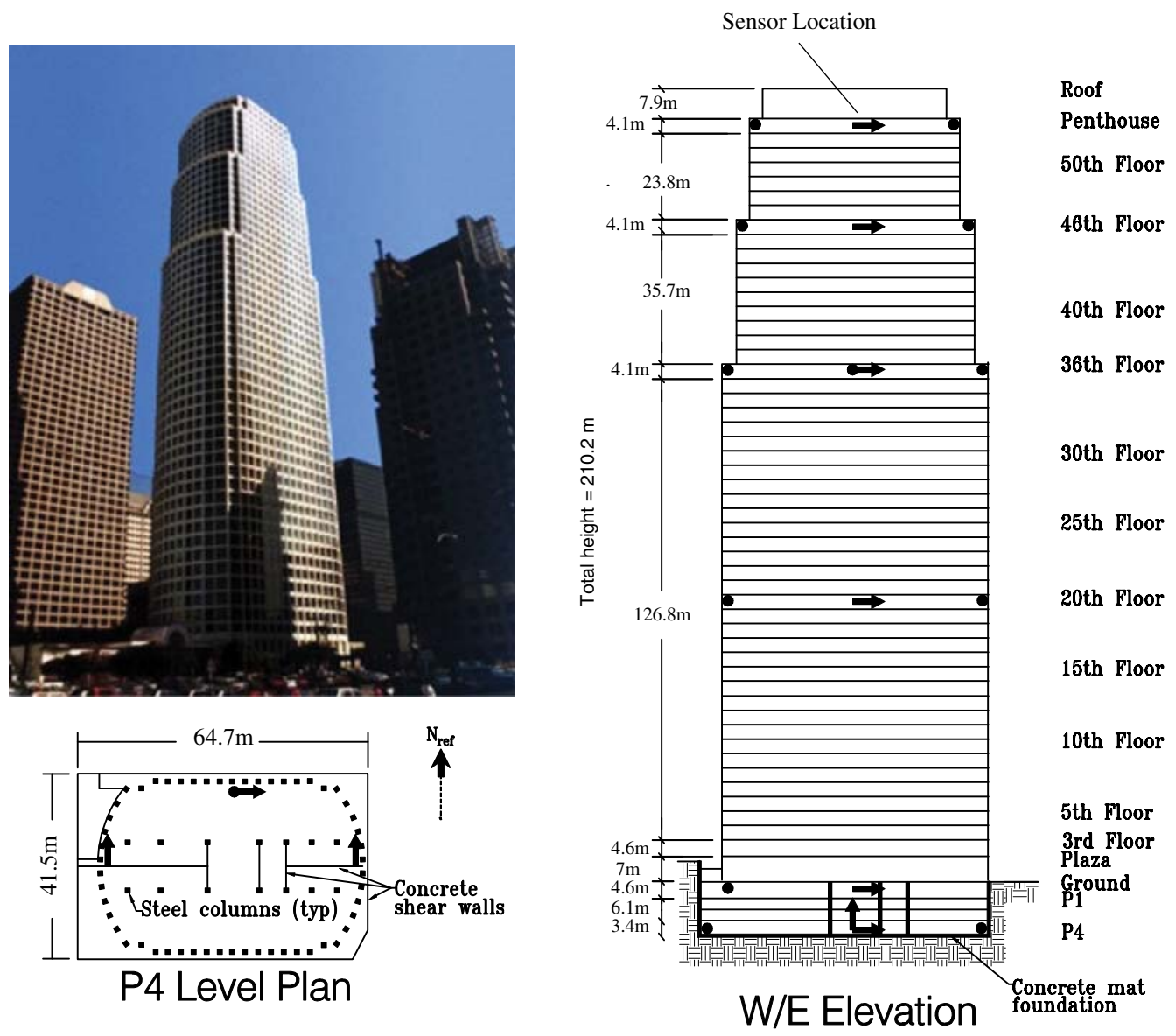

Figure 1. Photograph and diagrams of the 54-story building in downtown Los Angeles, California, showing building dimensions, floor heights, and seismic network configuration (from the Center for Engineering Strong Motion Data database, see Data and Resources). The color version of this figure is available only in the electronic edition.

$$
\hat{u}(t, z)=u_{w}(t, z) \times w_{w}(t, z)+u_{r}(t, z) \times w_{r}(t, z),
$$

in which $u_{w}(t, z)$ and $w_{w}(t, z)$ are the wave solution and weighting function for the wave solution; $u_{r}(t, z)$ and $w_{r}(t, z)$ are the resonant mode solution (see equation 2 ) and weighting function for the resonant mode solution. At subsequent times when wave attenuation and dispersion effects become significant, building motions cannot be easily modeled by the wave solution. The time $t$ discussed here is relative to the $S$-wave arrival time, and $t=0 \mathrm{~s}$ is defined here when the initial $S$ wave arrives at the base of the building.

We assume the initial impulse takes time $T_{1} / 4$ to travel up the building height $H$ (equal to the wave travel time in a shear beam), that is, wave velocity $c=(4 H) / T_{1}$, only in the first upward leg vertically along the building. The subsequent modal response solution capturing the low-frequency vibrating modes is identified either by fast Fourier transform analysis or by system identification methods (e.g., Overschee and Moor, 1994; Ljung, 1999; Clinton et al., 2006) applied to the seismic records (equation 2). Using the precalculated mode shapes that assumed a beam representation, the modal displacement responses on the other floors can be computed.

\section{Seismic Records from a 54-Story Building}

We present earthquake records of a 54-story office building in downtown Los Angeles, California, (Fig. 1) to describe our response prediction method. The 54-story building, constructed in 1991, is rectangular with base dimensions of $64.7 \mathrm{~m} \times 41.5 \mathrm{~m}$ and founded on a concrete mat foundation. The lateral resisting system is mainly composed of the moment-resisting perimeter steel frame with $3 \mathrm{~m}$ column spacing. There are Virendeel trusses and $14.6 \mathrm{~m}$ transfer girders at the 36th and 46th floors to accommodate the dislocations of vertical structural elements. The building is instrumented by the California Strong Motion Instrumentation Program, with accelerometers on the penthouse, 46th floor, 36th floor, 20th floor, ground floor, and the P4 underground level. Structural details and seismic records of this building can be found in the Center for Engineering Strong Motion Data database (see Data and Resources).

Rahmani and Todorovska (2014) suggested a layered shear beam and torsional shaft model and Ebrahimian and Todorovska (2014) suggested a layered Timoshenko beam model to represent the building. Records from several seismic stations in the building are required to construct their proposed 


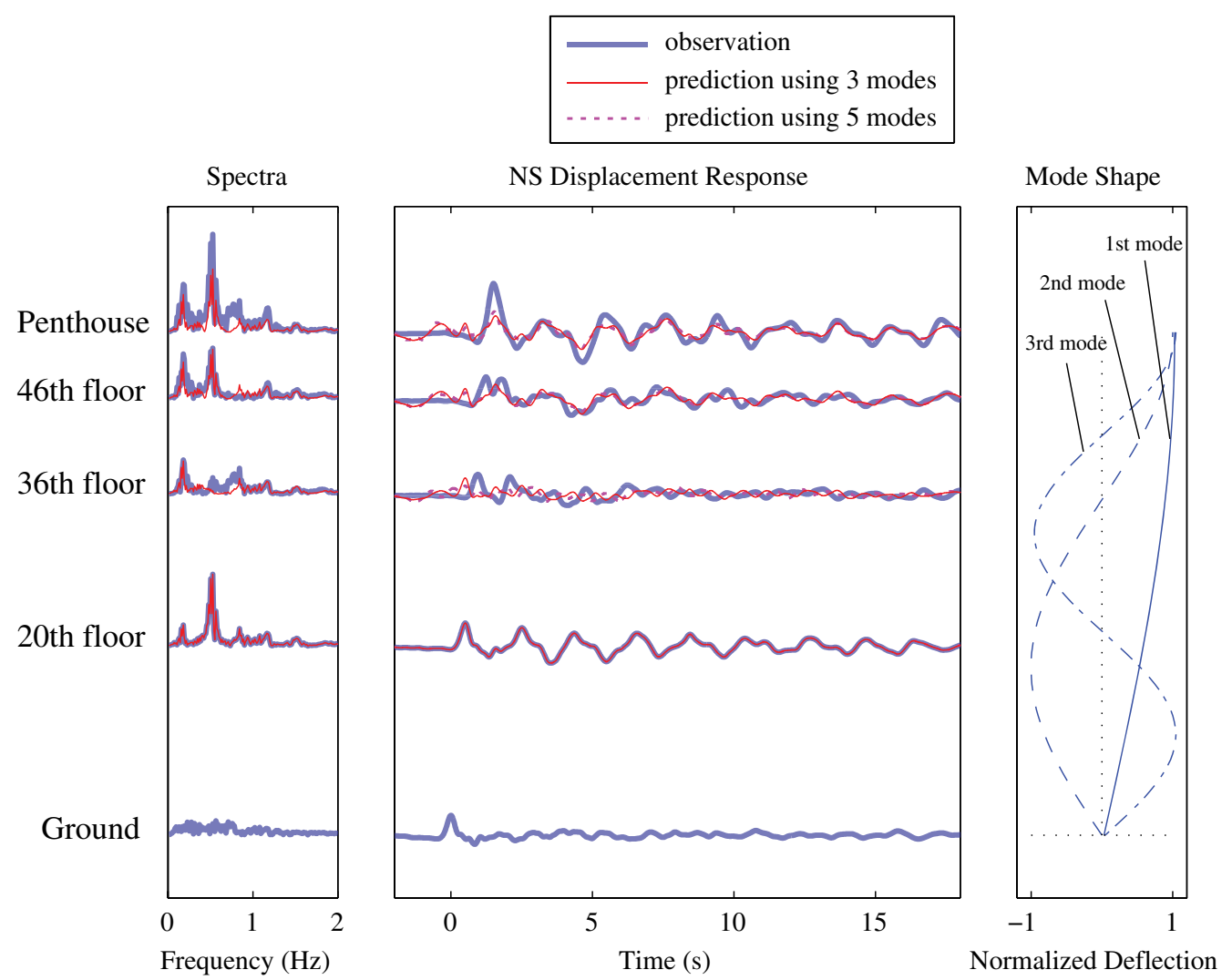

Figure 2. Simulated (based only on resonant mode solution) and observed displacement responses of the 54-story building in the north-south (NS) direction during the 2008 M 5.4 Chino Hills, California, earthquake. The vertical locations of the records are shown by the floor levels in the building. Displacement time series are normalized to the same scale by data from the penthouse, which has maximum absolute displacement of $1.45 \mathrm{~cm}$ and minimum absolute displacement of $-2.34 \mathrm{~cm}$. The color version of this figure is available only in the electronic edition.

models based on deconvolution interferometry. In this study, we will focus on building response prediction using only data from as few as a single seismometer and without the knowledge of a computational model for the building. We show that although our proposed method neglects the influence of torsion (which can be significant for tall buildings), our firstorder prediction agrees well with the measured data.

Figure 2 shows the recorded displacements in the northsouth direction of the 54-story building on the 20th, 36th, 46th, and penthouse floors during the 29 July 2008 M 5.4 Chino Hills, California, earthquake (epicentral distance $47 \mathrm{~km}$ ). The displacement spectra demonstrate that the building's displacement responses are dominated by the second north-south mode. The influence due to the first mode is significant, and there are lesser contributions from the third mode. The first, second, and third north-south modal frequencies of the building are observed to occur at 0.18 , 0.52 , and $0.84 \mathrm{~Hz}$. The natural frequency ratios are approximately 1,3 , and 5 , so we assume the mode shapes of this building are close to those of a fixed-base shear beam. In addition, an initial upward traveling impulse is observed at $t=0 \mathrm{~s}$ (Fig. 2). The first crest of the impulse is reflected at the roof at $t=1.5 \mathrm{~s}$, which is close to one-fourth of the building's fundamental period.
To demonstrate our method, we use the single record from the 20th floor to predict records from other floors. We first investigate the building response estimate solely based on resonant modes. As was previously mentioned, it is difficult to decompose the 20th floor record into the modal coordinate frame. To get around this limitation, we decompose the motions into the different modal coordinates by using a band-pass filter that is centered on the natural frequency of each mode to calculate the resonance response that is harmonic-like at the natural frequencies of the building. The difference between these harmonic resonances and the actual motions are ascribed to traveling waves. In this example, the 2008 Chino Hills earthquake displacement records are band-pass filtered with second-order, zero-phase Butterworth filters for frequencies $0.1-0.4 \mathrm{~Hz}$ for the first resonant mode, $0.4-0.7 \mathrm{~Hz}$ for the second resonant mode, and $0.7-1.0 \mathrm{~Hz}$ for the third resonant mode. The resonant mode (total) response $u_{r}(t, z)$ at height $z$ from the ground, constrained by data produced by a single seismometer at height $z_{s}$, can be approximated as

$$
\left.u_{r}(t, z)\right|_{\text {seismometer at } z_{s}} \approx \sum_{i=1}^{N}\left[f_{i}\left(t, z_{s}\right) \frac{\phi_{i}(z)}{\phi_{i}\left(z_{s}\right)}\right]+u_{\mathrm{rm}}\left(t, z_{s}\right)
$$


in which $t$ is time, $N$ is the number of vibrating modes observed in the seismic record, $f_{i}\left(t, z_{s}\right)$ is the filtered response (which represents the damped modal response) for the $i$ th mode for the single record at height $z_{s}, \phi_{i}(z)$ is the mode shape deflection value as a function of height $z$ for the $i$ th mode, and $u_{\mathrm{rm}}(t, z)$ is the residual motion after the filtered response component has been subtracted from the data at height $z_{s}$. Comparing with equation (3), we assume this residual motion $u_{\mathrm{rm}}(t, z)$ to be the part of the ground excitation that will be experienced by all the floors. It is computed as follows:

$$
u_{\mathrm{rm}}\left(t, z_{s}\right)=u_{r}\left(t, z_{s}\right)-\sum_{i=1}^{\text {number of modes }}\left[f_{i}\left(t, z_{s}\right)\right] .
$$

In other words, the filtered time series for different modes are related to the other floors using the corresponding mode shapes of the building, and damping is implicitly included in the floor response prediction.

The time series comparisons between the estimation from the 20th floor and the data are displayed in Figure 2. Even when we include two extra north-south modes (the fourth and fifth north-south modes at 1.16 and $1.51 \mathrm{~Hz}$; Rahmani and Todorovoska, 2014) in equation (5), the predicted floor displacement is very similar to the response using only the first three modes, as shown in Figure 2. The prediction solely based on modal decomposition using the first few modes does not adequately capture the initial upward traveling impulse from the ground, and it underestimates the peak floor response at the penthouse by a factor of more than 2 at $t \cong 1.5 \mathrm{~s}$. However, this harmonic modal estimation matches the seismic records for subsequent times after the initial impulse has reached the top of the building. Iwan (1997) mentioned that pulses travel through the buildings as waves, and the conventional techniques using modal superposition method and response spectrum analysis may not capture the effect of these pulses. They indicated that maximum floor response might occur during the coherent impulsive ground motions before the resonant mode response dominates.

\section{Building Response Prediction Using a Single Seismometer}

Because modal decomposition using the first few modes does not capture the initial traveling impulse during earthquakes, we use the traveling wave solution to capture the initial upward traveling impulse along the building height. The initial impulse is observed in the displacement record from the 20th floor of the 54-story building for the 29 July 2008 Chino Hills, California, earthquake (Fig. 3). This initial impulse shape is replicated on other floors according to the traveling shear-wavespeed estimated for this building, that is, wave velocity $c=(4 H) / T_{1}=(4 \times 210) / 5.83=144 \mathrm{~m} / \mathrm{s}$. We simulate this impulse for a cycle that includes one upward and one downward leg vertically along the building.
Using our approximated shear-wave velocity, we estimate the first crest of the impulse will arrive at the roof at time $t_{1}=1.5 \mathrm{~s}$, where it will be reflected and will reach the base of the building at time $t_{2}=2.9 \mathrm{~s}$. In this example, let $\mathrm{TS}_{b}(t)$ be the time series response before $t_{1}$ on the 20th floor; the value of $\operatorname{TS}_{b}(t)$ is zero for $t>t_{1}$. Similarly, let $\mathrm{TS}_{a}(t)$ be the time series response after $t_{1}$ on the 20th floor; thus the entire time series on the 20th floor is $\operatorname{TS}_{20 F}(t)=\mathrm{TS}_{b}(t)+\mathrm{TS}_{a}(t)$. This representation allows us to simply shift the time series $\mathrm{TS}_{b}(t)$ and $\mathrm{TS}_{a}(t)$ according to our estimated wave velocity to simulate the wave propagation effect up the building. The simulated wave solution for the initial impulse on the target floor $u_{w}(t, z)$ can then be expressed as

$$
u_{w}(t, z) \approx \mathrm{TS}_{b}\left(t-\frac{z-z_{s}}{c}\right)+\operatorname{TS}_{a}\left(t+\frac{z-z_{s}}{c}\right),
$$

in which $z_{s}$ is the height of the seismometer floor from the ground and $c$ is the wave velocity. In our example, $\left(z-z_{s}\right) / c$ is positive when the target floor is above the 20th floor (the single seismometer floor), which implies $\operatorname{TS}_{b}(t)$ and $\operatorname{TS}_{a}(t)$ will merge; $\left(z-z_{s}\right) / c$ is negative when the target floor is below the 20th floor, which implies $\operatorname{TS}_{b}(t)$ and $\operatorname{TS}_{a}(t)$ will diverge. In theory, the complete wave solution should include a damping function (like the one in equation 1). In our proposed method, this wave solution is only used between $t=0$ to $t_{2}$. Given the short traveling distance, the damping function is excluded for simplicity, and the simulated building response still matches the observation well. For the 54-story example, the simulated impulse travels up the building. Then we apply weighting functions according to the time $t_{1}$ and $t_{2}$ for the transition to the resonant mode responses (see equation 4 and Fig. 3). For subsequent times, the observed displacement record from the single seismometer is band-pass filtered with a second-order, zero-phase Butterworth filter on the first three resonant frequencies to get the damped modal response time series. Responses for the other floors are related to the 20th floor using the mode shapes of a fixed-base shear beam (equation 5).

Figures 4a,d,g,j and 5a,d,g,j show the results of the method applied to the 54-story building comparing the four different single seismometer inputs (20th, 36th, 46th, and penthouse floors) during the 29 July 2008 Chino Hills, California, earthquake. Unlike the mode-only solution, this method also models the initial traveling wave. Figures $4 \mathrm{a}$ and $5 \mathrm{a}$ show the predicted floor response time series and spectra using the record at the penthouse as input. The penthouse data successfully capture the first three modes, so the subsequent modal responses are well estimated on the other floors. The same applies to the data recorded on the 46th floor (Figs. 4d and 5d). The 36th floor is near a nodal point of the second mode, so the data do not capture any contribution from the second mode (Figs. $4 \mathrm{~g}$ and $5 \mathrm{~g}$ ). With only combinations of the first and third modes, the predicted responses on the other floors are somewhat degraded. Although the 20th floor is near a nodal point in the third mode, the prediction agrees with the observation using 


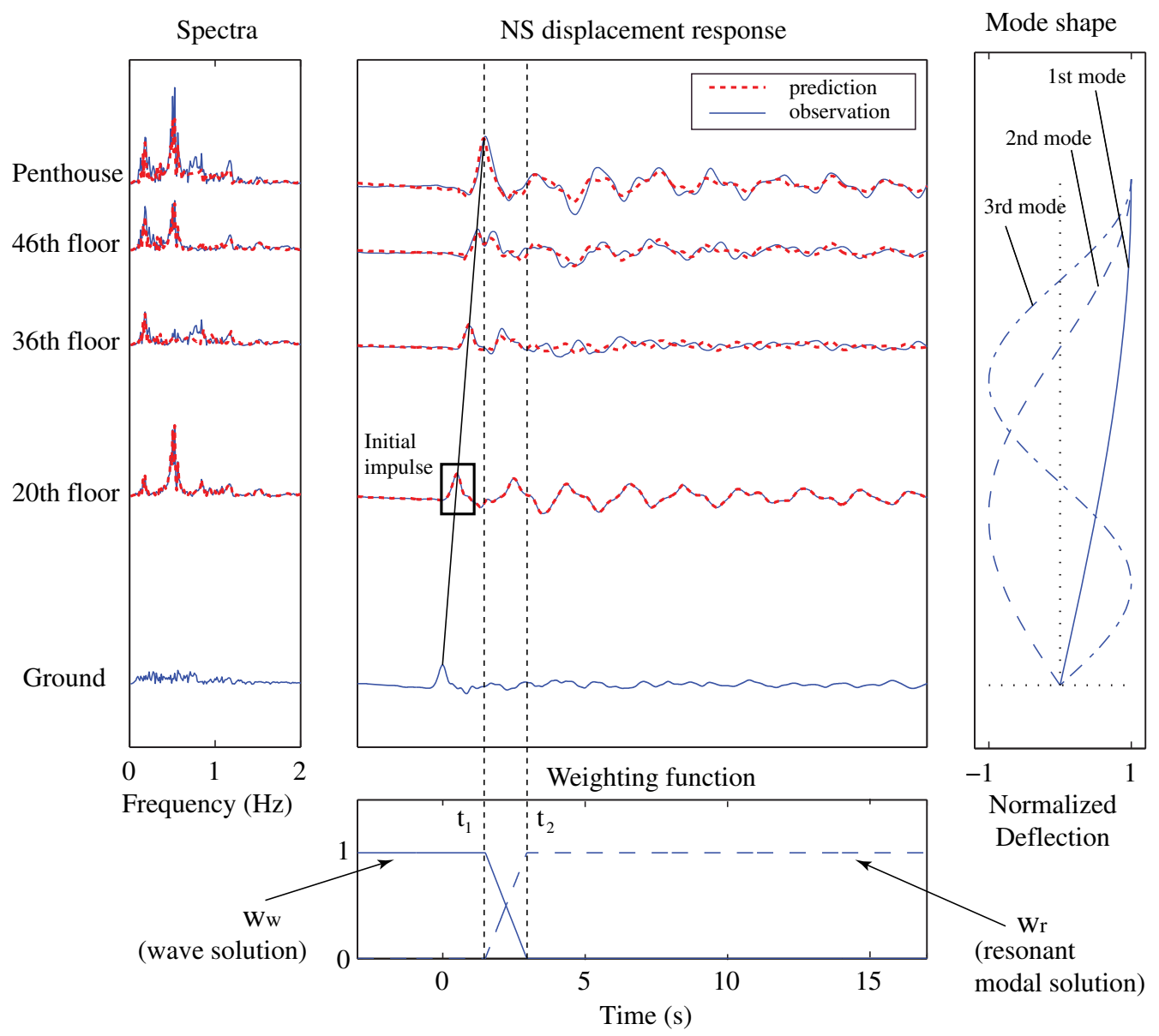

Figure 3. Simulated (based on the combined, weighted, traveling wave plus resonant mode method described in text) and observed displacement responses of the 54-story building in the north-south (NS) direction during the 2008 M 5.4 Chino Hills, California, earthquake. The vertical locations of the records are shown by the floor levels in the building. Displacement time series are normalized to the same scale by data from the penthouse, which has maximum absolute displacement of $1.45 \mathrm{~cm}$ and minimum absolute displacement of $-2.34 \mathrm{~cm}$. The color version of this figure is available only in the electronic edition.

only the information from the first and second modes (Figs. $4 \mathrm{j}$ and $5 \mathrm{j}$ ). Figures $4 \mathrm{~b}, \mathrm{e}, \mathrm{h}, \mathrm{k}$ and $5 \mathrm{~b}, \mathrm{e}, \mathrm{h}, \mathrm{k}$ show the results using the same method applied to records from the 28 June 1992 M 6.5 Big Bear, California, earthquake (epicentral distance $133 \mathrm{~km}$ ). Similar conclusions can be drawn.

The building's displacement response to the 4 April 2010 M 7.2 El Mayor-Cucapah earthquake (epicentral distance, $341 \mathrm{~km}$ ) was significantly larger in absolute amplitude than the two previously considered earthquakes, and the observed ground motion is much longer period. In this case, the longer-period ground excitation causes the building to respond mainly in its fundamental mode (Figs. 4c,f,i,l and $5 \mathrm{c}, \mathrm{f}, \mathrm{i}, \mathrm{l})$. We compare the ground motions for these three earthquakes recorded at the base of this building (Fig. 6) and observed that the durations of the initial ground impulse for the Chino Hills, the Big Bear, and the El Mayor-Cucapah earthquakes are approximately $0.7,1.3$, and $5.7 \mathrm{~s}$, respectively. The fundamental period, $T_{1}$, of this building is close to $5.8 \mathrm{~s}$ in the north-south direction. This observation suggests that when the duration of the initial ground impulse approaches $T_{1}$, the initial traveling wave will not be observed; instead resonant response from dominant vibrating modes is formed in the building during the ground excitation.

\section{Verification with a 3D Finite-Element Model}

To further illustrate and validate the traveling wave behavior of building response, we use a detailed finite-element model of a building to compute the transfer functions for impulsive excitation at the base of the building (i.e., the impulse response functions). Impulse response functions have been used extensively in the field of geophysics to capture the property of coherent waves between two seismic stations on the earth (e.g., Campillo and Paul, 2003; Denolle et al., 2013). Within a building, impulse response functions describe how waves travel up and down the building, as well as how waves are reflected from large-scale stiffness discontinuities in the building (e.g., Kohler et al., 2007; Ebrahimian and Todorovska, 2014). Moreover, interferometric methods such as ambient noise cross correlations also capture the impulsive response functions within a building, and closely 
2008 Chino Hills

(a)

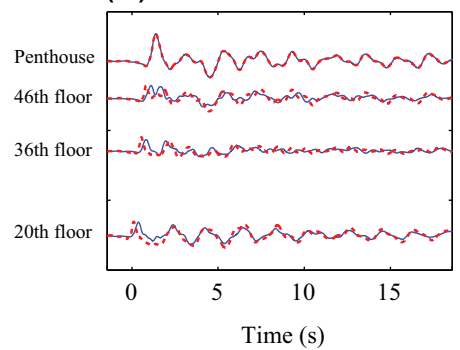

(d)

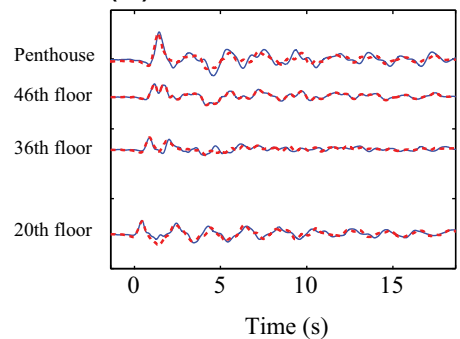

(g)

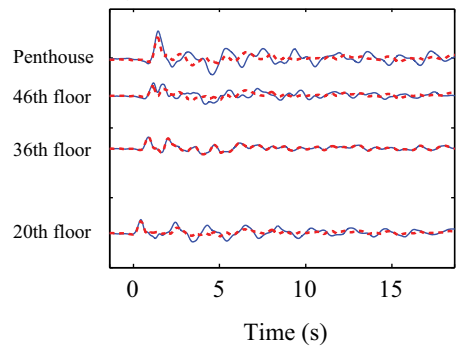

(j)

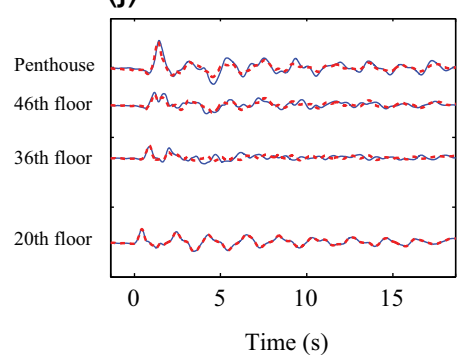

\begin{tabular}{|ll}
$\cdots \cdots \cdots$ & prediction \\
\hline & observation \\
\hline
\end{tabular}
1992 Big Bear

(b)

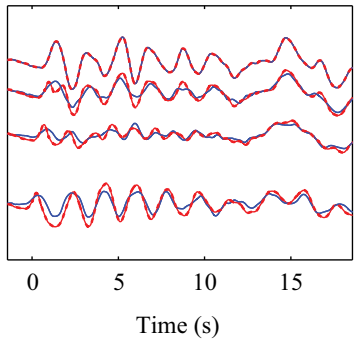

(e)

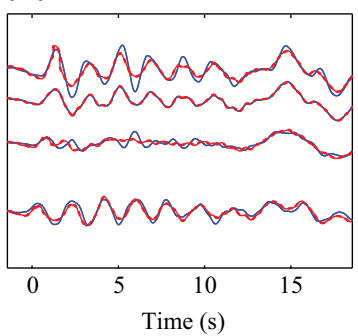

(h)

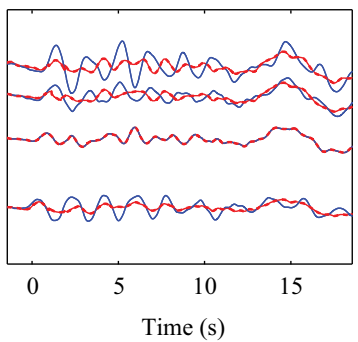

(k)

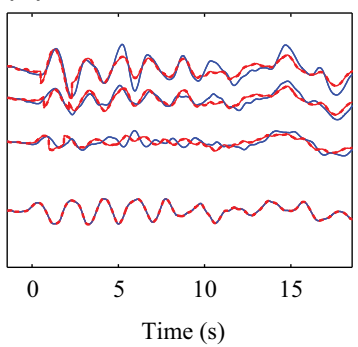

2010 El Mayor-Cucapah

(c)

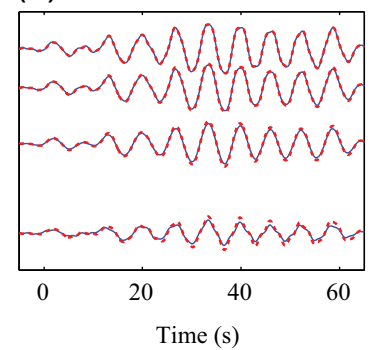

(f)

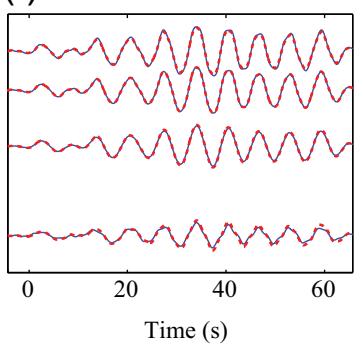

(i)

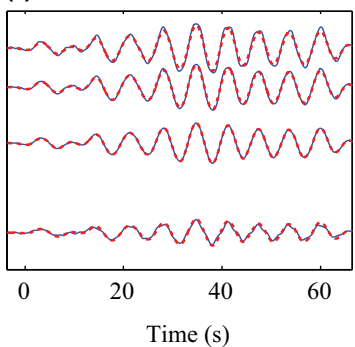

(l)

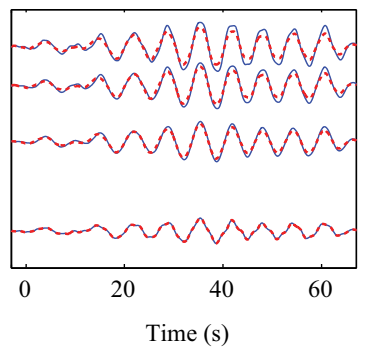

Figure 4. Displacement responses of the 54-story building in the north-south direction for the (a,d,g,j) 2008 Chino Hills, California, earthquake; (b,e,h,k) 1992 Big Bear, California, earthquake; and (c,f,i,l) 2010 El Mayor-Cucapah earthquake. (a-c) Prediction using the record from the penthouse. (d-f) Prediction using the record from the 46th floor. ( $\mathrm{g}-\mathrm{i})$ Prediction using the record from the 36th floor. (j-l) Prediction using the record from the 20th floor. The color version of this figure is available only in the electronic edition.

match the shear-wave velocities observed in the earthquakebased impulse response functions (Prieto et al., 2010). In theory, these impulse response functions account only for the wave propagation effect due to elastic properties between any pair of seismometers.

The Doris and Louis Factor building on the University of California, Los Angeles (UCLA) campus is a 17-story steel moment-resisting frame structure with two basement levels (Fig. 7a,b). It is an example of a building type that deforms primarily in shear. The first two north-south modal frequencies are 0.59 and $1.83 \mathrm{~Hz}$, whereas the first two eastwest modal frequencies are 0.55 and $1.70 \mathrm{~Hz}$ (Kohler et al., 2007). Kohler et al. (2007) constructed a 3D finite-element model using ETABS software (see Data and Resources) to study the wave-propagation behavior of the Factor building in the linear elastic regime (Fig. 7c-e). Details of the model are based on structural engineering drawings of the building. The structural core of the Factor building is a double-moment 
(a)

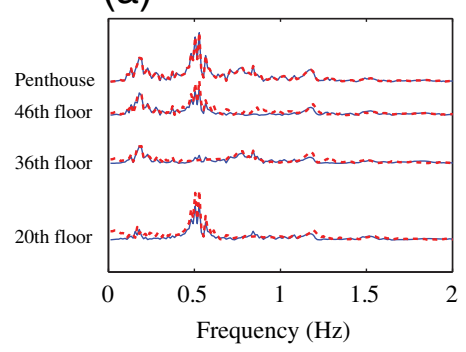

(d)

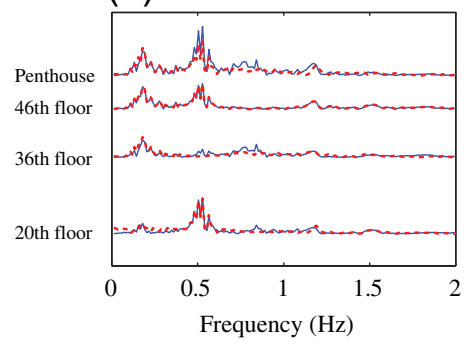

(g)

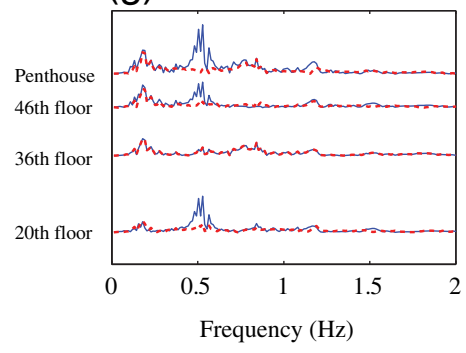

(j)

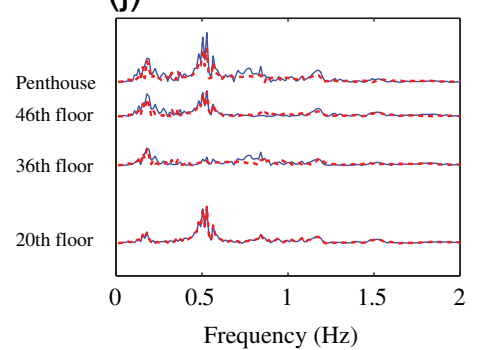

1992 Big Bear

(b)

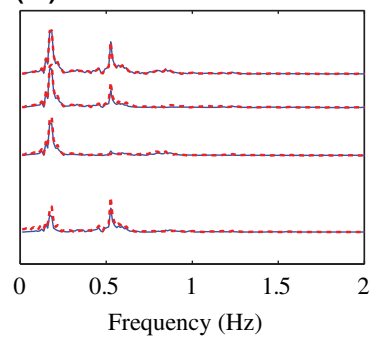

(e)

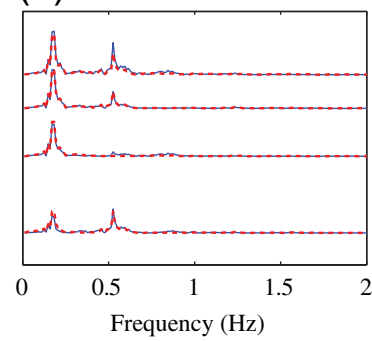

(h)

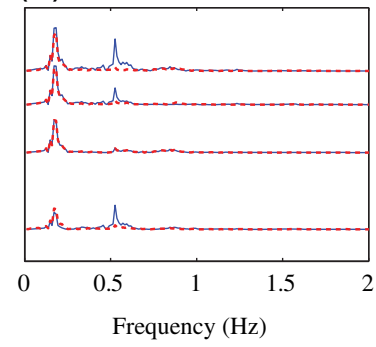

(k)

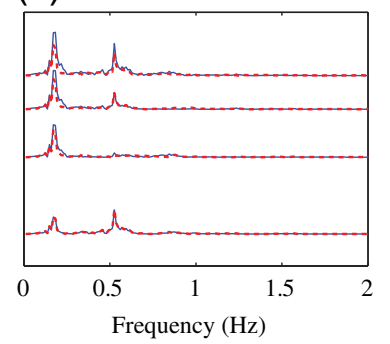

2010 El Mayor-Cucapah

(c)

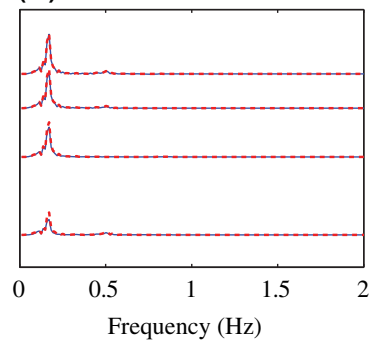

(f)

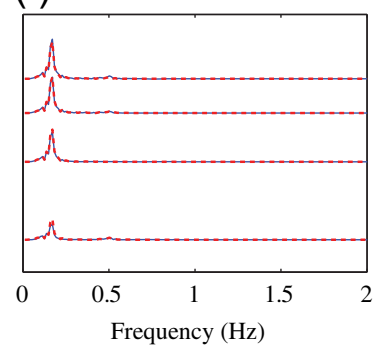

(i)

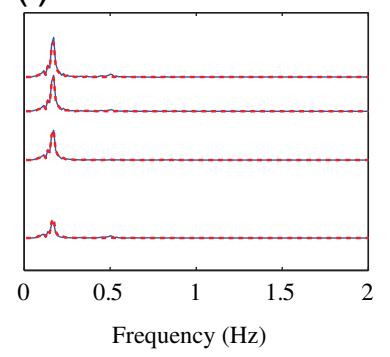

(I)

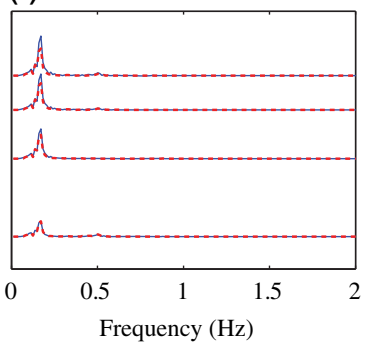

\begin{tabular}{ll}
$\cdots \cdots \cdots$ & prediction \\
& observation \\
\hline
\end{tabular}

Figure 5. Displacement spectra of the 54-story building in the north-south direction for the (a,d,g,j) 2008 Chino Hills, California, earthquake; (b,e,h,k) 1992 Big Bear, California, earthquake; and (c,f,i,l) 2010 El Mayor-Cucapah earthquake. (a-c) Prediction using the record from the penthouse. ( $d-f)$ Prediction using the record from the 46th floor. (g-i) Prediction using the record from the 36th floor. ( $j-1$ ) Prediction using the record from the 20th floor. The color version of this figure is available only in the electronic edition.

bay, and this bay provides the lateral stiffness required to meet the demands of the structure. The other nonmoment frames are primarily used to carry gravity load. Moment frames of the building are modeled using beam and column elements with moment-resisting connections; the remaining connections are modeled as pinned connections. Floors and interior walls of the building are replaced with distributed mass elements, and the mass is vertically lumped at each floor.
We input a Gaussian shape displacement impulse with duration of $T_{1} / 15$ (in which $T_{1}$ is the fundamental natural period of the building in the north-south direction) at the base of the finite-element model to compute the impulse response functions in the north-south direction. We begin with the relatively small value of $T_{1} / 15$ to examine the effects of an impulse duration much less than $T_{1}$. Figure 8 a shows that the impulse is reflected off the underside of the roof as well as at the base of the building. Initially, the impulse takes time 
(a)

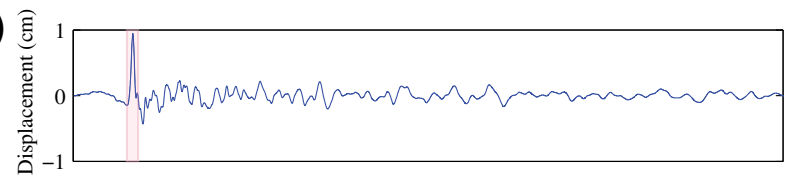

(b)

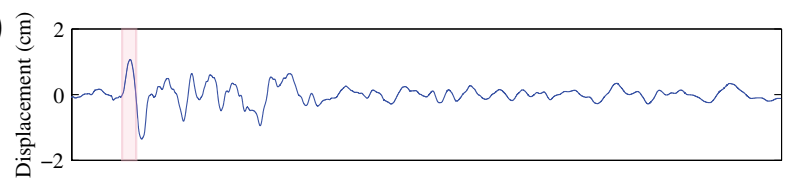

(c)

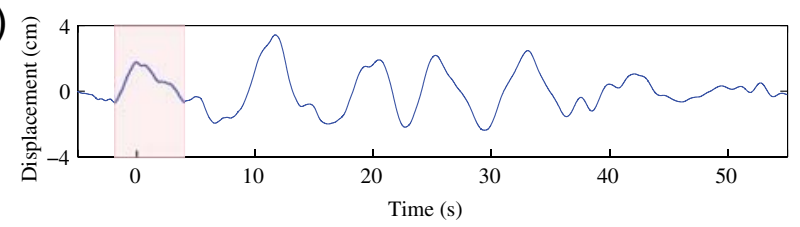

Figure 6. Observed displacement at the ground level of the 54story building in the north-south direction for the (a) 2008 Chino Hills, California, earthquake (epicentral distance 47 km), (b) 1992 Big Bear, California, earthquake (epicentral distance $133 \mathrm{~km}$ ), and (c) $2010 \mathrm{El}$ Mayor-Cucapah earthquake (epicentral distance, $341 \mathrm{~km}$ ). The color version of this figure is available only in the electronic edition.

$T_{1} / 4$ to travel up the building from the base, which exactly equals the time required by a theoretical shear beam. The impulse maintains its amplitude and phase as it travels vertically from the base to the roof. When it arrives at the roof, constructive interference between the initial upward and the reflecting waves occurs. Afterward, wave attenuation and dispersion become significant. Because different frequency components of that impulse begin to travel at different speeds with reduced amplitudes, the impulse cannot maintain its initial shape.

In theory, we can convolve the impulse response functions with any earthquake ground motions to obtain the linear elastic response of each floor. Figure $8 \mathrm{~b}$ shows the simulated displacement response for the Factor model in the northsouth direction for the 2008 Chino Hills earthquake. Similar to the impulse response functions, an impulse first travels up the building with consistent amplitude and phase. After it is reflected from the roof of the building, the impulse cannot maintain its initial shape. Although the earthquake triggers continuous motion at the base of the building, standing waves (associated with the vibrating modes of the building) due to upward and downward traveling waves are formed. The resulting modal response in displacement is typically dominated by the first 2-3 resonant vibrating modes of the building (e.g., Chopra and Goel, 2002).

\section{Effect of Impulse Duration on Traveling the Wave}

We next use the Factor model to investigate the effect of initial impulse duration in the ground motion on the building response (Fig. 9). For impulse duration times much smaller than $T_{1}$, the initial upward traveling impulse is observed, and it takes time $T_{1} / 4$ to travel from the base to the roof of the building, with the subsequent response dominated by the resonant modes (Fig. 9a). Similar simulation results are observed for increasingly long impulse duration times (time $=T_{1} / 2$, as shown in Fig. $9 \mathrm{~b}$ ), until the impulse duration approaches $T_{1}$ (Fig. 9c). When the impulse duration is larger than $T_{1}$, resonant modes (in-phase motions) are mixed into the initial upward traveling impulse. The initial impulse now takes less time to travel from the base to the roof of the building. For example, based on the point at the top of the wave crest, the travel time from base to roof is $T_{1} / 5.5$ for an impulse with duration of $1.5 T_{1}$. When the initial impulse duration time is long enough $\left(t=2.5 T_{1}\right)$ and longer than the fundamental period, the building oscillates like a rigid body together with the ground motion, and the initial upward traveling wave is no longer observed (Fig. 9d). Interference between upward and reflected traveling waves becomes increasingly complex for long-period waves because the waves are no longer impulsive for these building height and shearwavespeed scales. This will affect the resolution and accuracy of the measured impulse propagation time, making inferences about pulse propagation velocity for long periods impossible over the scale of a building height (Todorovska and Rahmani, 2013).

Construction of accurate, detailed 3D finite-element models of instrumented buildings depends on the access to structural engineering drawings of the buildings, which are often not available. If a building is instrumented on every floor, we can obtain the transfer functions by deconvolving the displacement responses on all floors with the nearby free-field ground motion. In practice, this can also be approximated by deconvolving the upper floor displacements with the base motion of the building. This procedure is an approximation because the base of the building is assumed to be fixed during the building's transient motions. If the building is only instrumented with a single seismometer, transfer functions between each floor's response and the base motion cannot be obtained. The results in this study validate the idea of using a single recorded impulse as a template for the traveling wave and applying this template to other floors through an estimated wavespeed for the initial traveling cycle.

In the majority of observations, large-amplitude traveling waves are due to near-source directivity effects and occur during the initial onset arrival of $S$ waves. When fault rupture propagates toward the receiver site and the shear-wave velocity is similar to the rupture velocity, a large-amplitude velocity pulse may form at the beginning of the ground motion in the strike-normal direction. The likelihood of pulse occurrence depends on the site-to-source geometry, earthquake magnitude, and other characteristics (Somerville et al., 1997; Tothong et al., 2007; Casey and Liel, 2012). These nearsource pulse-like ground motions may induce large displacement and strength demands in buildings (Hall, 1998; Iwan, 1999). Our proposed method is expected to accurately capture the linear elastic displacement response of a building in these cases. However, there may be uncommon instances in which subsequent large-amplitude pulses occur in the ground motion after $t=t_{2}$, which may be due, for example, to scat- 
(a)

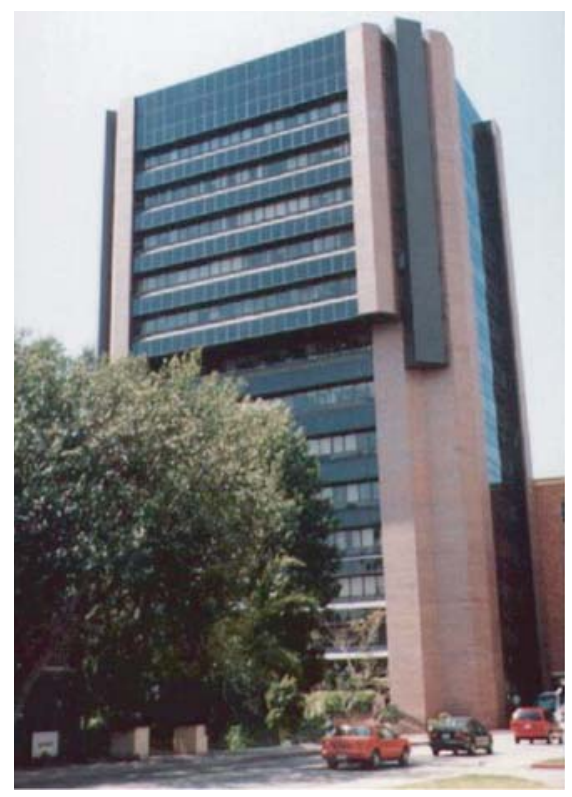

(b)

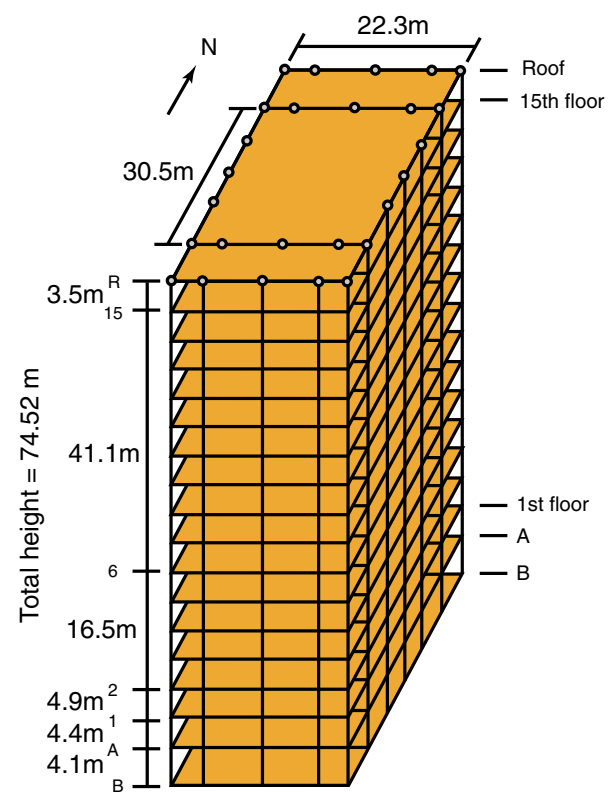

(c)

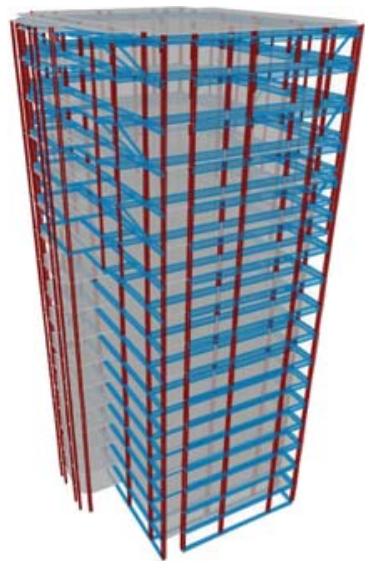

(d)

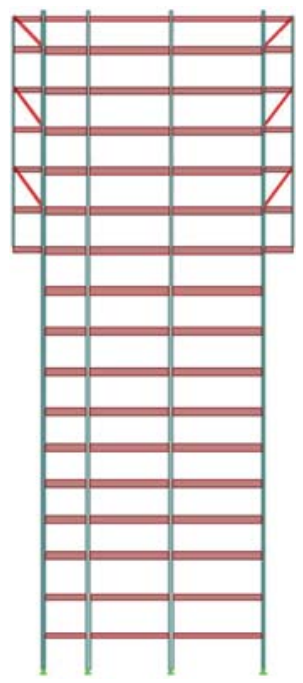

East-West cross section (e)

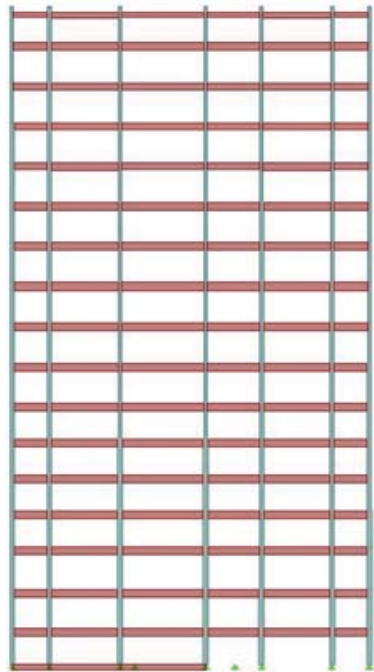

North-South cross section

Figure 7. (a,b) University of California, Los Angeles (UCLA) Factor building showing building dimensions and floor heights. (c-e) The ETABS finite-element model of the Factor building (from Kohler et al., 2007). The color version of this figure is available only in the electronic edition.

tering in a thin, low-velocity layer below the earth's surface. In such cases, the modal response solution that we used for times after $t=t_{2}$ may not capture the subsequent largeamplitude pulses (as discussed earlier in this article).

\section{Conclusions}

The main advantages of the proposed method of estimating the linear elastic displacement response of a building are that it is fast and robust, and that data from only a single seismometer are needed to provide constraints. Differential equations associated with dynamic response theory are not required to compute the displacement response. The initial upward-traveling impulse can be approximated by the wave solution, and the impulse velocity is related to the fundamental period of the building. The subsequent displacement response can be approximated by the resonant mode solution, which can be extracted from the observations with appropriate band-pass filters. Our results illustrate that the roof is the best choice for instrumentation, because this location is not a 

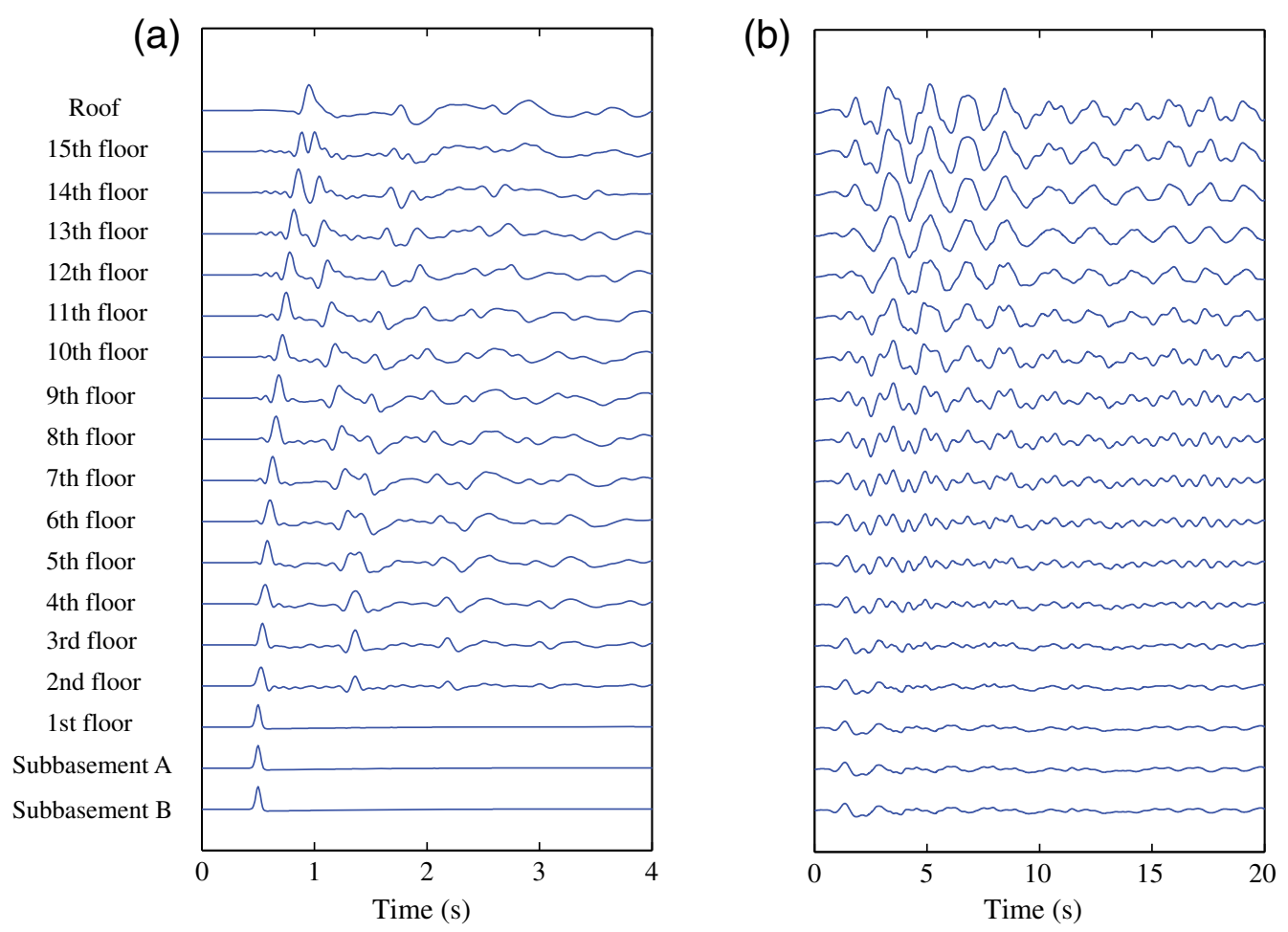

Figure 8. Simulation results using the Factor building finite-element model: (a) impulse response functions, and (b) simulated displacement responses in the north-south direction for the 2008 Chino Hills, California, earthquake. The vertical locations of the records are shown by the floor levels. Displacement for the time series are normalized to the same scale by the response at the roof, which has a maximum absolute displacement of $7.4 \mathrm{~mm}$ and minimum absolute displacement of $-6.9 \mathrm{~mm}$. The color version of this figure is available only in the electronic edition.

nodal point in any resonant modes, thus it will capture all the dominant modal responses during a seismic event. Our case study with the 54-story building shows that a sensor located on lower floors will not affect the displacement response predictability unless the single station is located on a floor level near a nodal point of the dominant resonant modes.

The buildings considered in this study exhibit shear beam behavior. If the natural frequency ratios of the target building are different from those of a shear beam, then mode shapes from a Timoshenko beam can be adopted when significant flexural response is observed. Cheng and Heaton (2013) developed a Timoshenko beam model with lateral and rotational springs at the base, which simulate the soilstructure interaction effect, to approximate the dynamic linear elastic behavior of the buildings. Mode shapes can be closely approximated by the knowledge of the natural frequencies of the first two translational modes in a particular direction of the building and the building dimensions. In many cases, the natural frequencies of the first two vibrational modes of a building can be determined from data recorded by a single seismometer. Application of the Timoshenko beam approach to infer response of 9- and 11-story reinforced concrete shear wall buildings shows that the application is straightforward (Kohler et al., 2013, 2014). Of course, inclusion of bending in the problem means that the traveling waves are dispersive and their shape changes as they propagate.
Therefore, we will restrict our model to buildings that are only mildly deviated from a shear beam, and we will only use nondispersive propagating wave solutions for waves that have propagated short distances. In the case of two buildings used in this study, the effects of bending appear to be relatively minor, and these buildings are simulated with the special case in which the beam deforms only in shear (i.e., a shear beam).

The duration of the ground-motion impulse has a pronounced effect on the relative significance of the initial traveling wave. We expect the initial impulse will take time $T_{1} / 4$ to travel from the base to the roof of the building. If the impulse duration is less than $T_{1} / 4$, the propagation of the impulse will be observed in the floor responses, and maximum floor response may occur during this period before the resonant mode response dominates. If the impulse duration is long enough, the building may oscillate together with the ground motion, and the initial upward traveling wave will not be observed. This phenomenon happens when impulse duration approximately equals $T_{1}$ for the 54-story building during the 2010 El Mayor-Cucapah earthquake and 2.5T for the finite-element model of the Factor building.

The method presented here is well suited to simulating building motions on multiple floors using data from new and expanding crowd-sourced seismic networks in which volunteers install inexpensive seismometers in their homes and offices in high-rise buildings. The Community Seismic Net- 
(a)

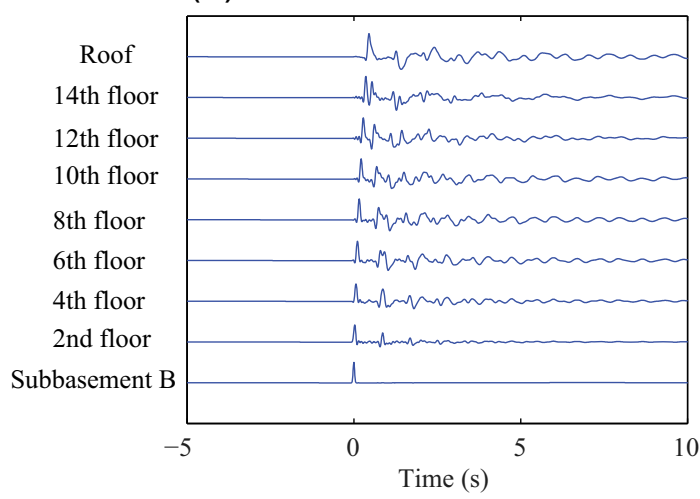

(c)

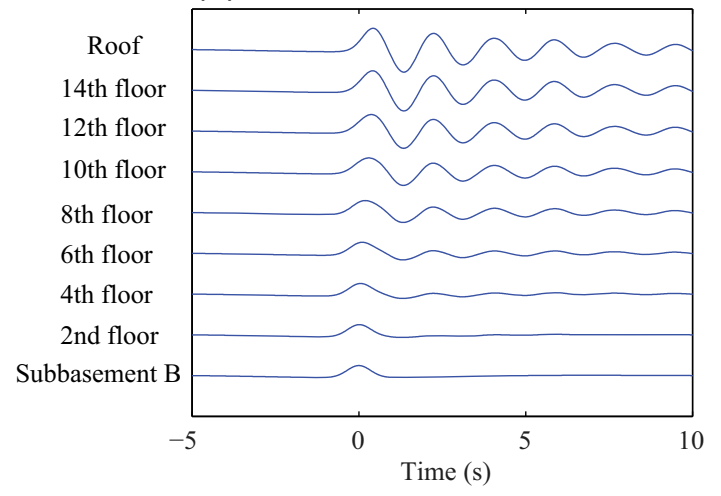

(b)

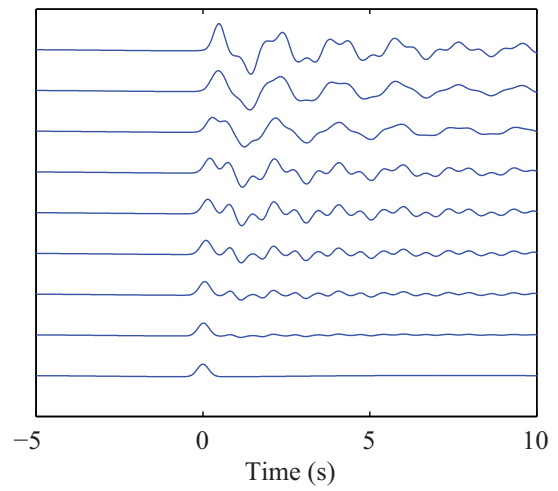

(d)

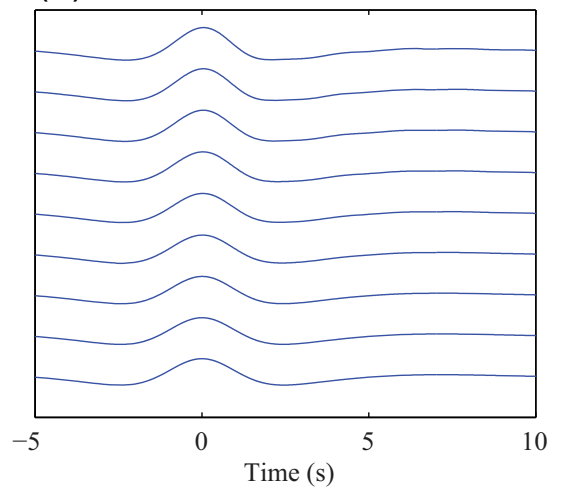

Figure 9. Comparison of the effects of varying the impulse duration on the Factor building finite-element model simulation results: impulse duration is (a) $T_{1} / 15$, (b) $T_{1} / 2$, (c) $T_{1}$, and (d) $2.5 T_{1}$. ( $T_{1}$ is the fundamental period of the building.) The color version of this figure is available only in the electronic edition.

work (Clayton et al., 2011) and Quake-Catcher Network (Cochran et al., 2009, 2011) are examples. In a crowdsourced network, station locations are typically chosen for reasons that are unrelated to (and may not be able to take advantage of) the optimal design and configuration of a seismic network. Furthermore, there may be instances in which a single seismometer is the only data stream available from a building. Our method indicates that even a single data stream input can be suitable for estimating entire-building response. In addition, our modeling results can be imported into 4D visualizations of building responses due to an earthquake or other shaking event. The products can raise the social interest in and awareness of the earthquake hazard. Visualization products such as movies of floor displacement responses allow the nonscientific community to learn how buildings responded to an earthquake. Kohler et al. (2013, 2014) show that 3D geometry-based models of buildings can be constructed using SketchUp, a 3D modeling program initially developed by Google for Google Earth, and can be easily transferred into 3D mesh models for quantitative processing using MATLAB, for example.

The technique presented here also meets needs in the field of hazard management. For example, roof deformation may be an indirect measure of the intensity of the shaking, as well as a potential measure of damage (Crowley et al., 2004; Medina and Krawinkler, 2005). It can provide rapid interpretation of the extent of potential damage by comparing the estimated response to the allowable elastic limit. The estimated intensity of shaking can be customized for a particular structure when data are available from that structure, and it can be made actionable. Last but not least, this study can be used to develop earthquake early warning applications for buildings, such as automated elevator control based on the estimated levels of shaking on different floors (Cheng et al., 2014).

\section{Data and Resources}

Seismic records in the Center for Engineering Strong Motion Data were searched using http://www.strongmotioncenter .org (last accessed January 2014). The ETABS software is distributed by Computers and Structures Inc.

\section{Acknowledgments}

This work is partially supported by the National Science Foundation (EAR-1027790), George Housner Earthquake Engineering Research Endowment (EAS-41212), Fred L. Hartley Family Foundation, and the Croucher Foundation. Their support is gratefully acknowledged. The authors are grateful to an anonymous reviewer and M. I. Todorovska for their constructive comments, which significantly improved the article. 


\section{References}

Campillo, M., and A. Paul (2003). Long-range correlations in the diffuse seismic coda, Science 299, no. 5606, 547-549.

Casey, C., and A. Liel (2012). The effect of near-fault directivity on building seismic collapse risk, Earthq. Eng. Struct. Dyn. 41, no. 10, 1391-1409.

Cheng, M. H., and T. H. Heaton (2013). Simulating building motions using the ratios of its natural frequencies and a Timoshenko beam model, Earthq. Spectra, doi: 10.1193/011613EQS003M.

Cheng, M. H., S. Wu, T. H. Heaton, and J. L. Beck (2014). Earthquake warning application to buildings, Eng. Struct. 60, 155-164.

Chopra, A. K., and R. K. Goel (2002). A modal pushover analysis procedure for estimating seismic demands for buildings, Earthq. Eng. Struct. Dyn. 31, 561-582.

Clayton, R., T. Heaton, M. Chandy, A. Krause, M. Kohler, J. Bunn, M. Olson, M. Faulkner, M. H. Cheng, L. Strand, R. Chandy, D. Obenshain, A. Liu, and M. Aivazis (2011). Community seismic network, Ann. Geophys. 54, no. 6, 738-747.

Clinton, J. F., S. C. Bradford, T. H. Heaton, and J. Favela (2006). The observed wander of the natural frequencies in a structure, Bull. Seismol. Soc. Am. 96, no. 1, 237-257.

Cochran, E. S., J. F. Lawrence, C. Christensen, and R. S. Jakka (2009). The Quake-Catcher Network: Citizen science expanding seismic horizons, Seismol. Res. Lett. 80, no. 1, 26-30.

Cochran, E. S., J. F. Lawrence, A. Kaiser, B. Fry, A. Chung, and C. Christensen (2011). Comparison between low-cost and traditional MEMS accelerometers: A case study from the M 7.1 Darfield, New Zealand, aftershock deployment, Ann. Geophys. 54, no. 6, 728-737.

Crowley, H., R. Pinho, and J. J. Bommer (2004). A probabilistic displacement-based vulnerability assessment procedure for earthquake loss estimation, Bull. Earthq. Eng. 2, 173-219.

Denolle, M. A., E. M. Dunham, G. A. Prieto, and G. C. Beroza (2013). Ground motion prediction of realistic earthquake sources using the ambient seismic field, J. Geophys. Res. 118, 1-17.

Ebrahimian, M., and M. Todorovska (2014). Wave propagation in a Timoshenko beam building model, J. Eng. Mech. 140, no. 5, doi: 10.1061/ (ASCE)EM.1943-7889.0000720.

Hall, J. F. (1998). Seismic response of steel frame buildings to near-source ground motions, Earthq. Eng. Struct. Dyn. 27, 1445-1464.

Iwan, W. D. (1997). Drift spectrum: Measure of demand for earthquake ground motions, J. Struct. Eng. 123, no. 4, 397-404.

Iwan, W. D. (1999). Implications of near-fault ground motion for structural design, in US-Japan Workshop on Performance-Based Earthquake Engineering Methodology for Reinforced Concrete Building Structures, Maui, Hawaii, 13 September 1999, PEER Report 1999/10, 17-25.

Jennings, P. C. (2003). An introduction to the earthquake response of structures, in International Handbook of Earthquake and Engineering Seismology, W. H. K. Lee, H. Kanamori, P. C. Jennings, and C. Kisslinger (Editors), Vol. 81, Part B, Academic Press, Burlington, Massachusetts, $1097-1125$.

Kanai, K. (1965). Some new problems of seismic vibrations of a structure, Proc. of the Third World Conf. Earthquake Eng., Auckland, New Zealand, 22 January-1 February 1965.

Kohler, M. D., T. H. Heaton, and S. C. Bradford (2007). Propagating waves in the steel, moment-frame Factor building recorded during earthquakes, Bull. Seismol. Soc. Am. 97, no. 4, 1334-1345.
Kohler, M. D., T. H. Heaton, and M. H. Cheng (2013). The Community Seismic Network and Quake-Catcher Network: Enabling structural health monitoring through instrumentation by community participants, Proc. of SPIE: Sensors and Smart Structures Technologies for Civil Mechanical, and Aerospace Systems, San Diego, California, 10-14 March 2013

Kohler, M. D., T. H. Heaton, M. H. Cheng, and P. Singh (2014). Structural health monitoring through dense instrumentation by community participants: The community seismic network, Proc. of the 10th US National Conference on Earthquake Engineering, Anchorage, Alaska, 21-25 July 2014.

Ljung, L. (1999). System Identification: Theory for the User, Second Ed., Prentice Hall, Upper Saddle River, New Jersey.

Medina, R., and H. Krawinkler (2005). Evaluation of drift demands for the seismic performance assessment of frames, J. Struct. Eng. 131, 1003-1013.

Overschee, P. V., and B. D. Moor (1994). N4SID: Subspace algorithms for the identification of combined deterministic-stochastic systems, Automatica 30, no. 1, 75-93.

Prieto, G. A., J. F. Lawrence, A. I. Chung, and M. D. Kohler (2010). Impulse response of civil structures from ambient noise analysis, Bull. Seismol. Soc. Am. 100, no. 5A, 2322-2328.

Rahmani, M., and M. I. Todorovska (2014). 1D system identification of a 54-story steel frame building by seismic interferometry, Earthq. Eng. Struct. Dyn. 43, 627-640.

Roberts, M. W., and L. D. Lutes (2003). Potential for structural failure in the seismic near field, J. Eng. Mech. 129, no. 8, 927-934.

Sasani, M., N. Makris, and B. A. Bolt (2006). Damping in shear beam structures and estimation of drift response, J. Eng. Mech. 132, no. $8,851-858$.

Snieder, R., and E. Safak (2006). Extracting the building response using seismic interferometry: Theory and application to the Millikan Library in Pasadena, California, Bull. Seismol. Soc. Am. 96, 586-598.

Somerville, P. G., N. F. Smith, R. W. Graves, and N. A. Abrahamson (1997). Modification of empirical strong ground motion attenuation relations to include the amplitude and duration effects of rupture directivity, Seismol. Res. Lett. 68, no. 1, 199-222.

Todorovska, M. I., and M. Rahmani (2013). System identification of buildings by wave travel time analysis and layered shear beam modelsSpatial resolution and accuracy, Struct. Control Health Monit. 20, no. 5, 686-702.

Tothong, P., C. A. Cornell, and J. W. Baker (2007). Explicit directivity-pulse inclusion in probabilistic seismic hazard analysis, Earthq. Spectra 23, no. $4,867-891$.

California Institute of Technology

MC 104-44

1200 E California Boulevard

Pasadena, California 91125

mmhcheng@caltech.edu

Manuscript received 7 February 2014; Published Online 23 December 2014 